\title{
Determination of Lamotrigine in Pharmaceutical Preparations by Adsorptive Stripping Voltammetry Using Screen Printed Electrodes
}

\author{
Olga Domínguez-Renedo, M. Encarnación Burgoa Calvo and M. Julia Arcos-Martínez * \\ Departamento de Química, Área de Química Analítica, Facultad de Ciencias, Universidad de Burgos, \\ Plaza Misael Bañuelos s/n, E-09001 Burgos, Spain; E-Mails: olgado@ubu.es; meburgoa@ubu.es \\ * Author to whom correspondence should be addressed; E-mail: jarcos@ubu.es; \\ Tel.: +34-947-258817; Fax: +34-947-258831
}

Received: 5 June 2008; in revised form: 25 June 2008 / Accepted: 10 July 2008 /

Published: 15 July 2008

\begin{abstract}
This paper describes a procedure that has been optimized for the determination of lamotrigine by Differential Pulse Adsorptive Stripping Voltammetry (DPAdSV) using carbon screen-printed electrodes (CSPE) and mercury coated carbon screen-printed electrodes. Selection of the experimental parameters was made using experimental design methodology. The detection limit found was $5.0 \times 10^{-6} \mathrm{M}$ and $2.0 \times 10^{-6} \mathrm{M}$ for the non modified and $\mathrm{Hg}$ modified CSPE, respectively. In terms of reproducibility, the precision of the above mentioned methods was calculated in \%RSD values at $9.83 \%$ for CSPE and $2.73 \%$ for $\mathrm{Hg}$-CSPE. The $\mathrm{Hg}$-coated CSPEs developed in this work were successfully applied in the determination of lamotrigine in pharmaceutical preparations.
\end{abstract}

Keywords: lamotrigine; screen-printed electrodes; differential pulse adsorptive stripping voltammetry.

\section{Introduction}

Lamotrigine (LTG), 3,5-diamino-6-(2,3-dichlorophenyl)-1,2,4-triazine (Figure 1) is a newgeneration antiepileptic drug registered for treatment of patients with refractory partial seizures with or without secondary generalization [1, 2]. It acts by inhibiting presynaptic voltage-sensitive sodium channels and excitatory neurotransmitter release. 
Figure 1. Chemical structure of lamotrigine.

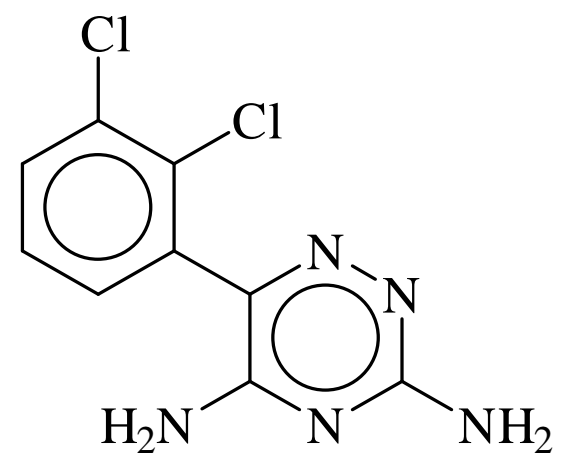

HPLC [3-7] and capillary electrophoresis [8] are among the different techniques generally used for the measurement of LTG concentrations in pharmaceutical products and biological fluids. Despite the presence of redox groups in this molecule, only one article in currently available in the literature describes the analysis of LTG by means of electrochemical techniques using a HMDE electrode and adsorptive stripping voltammetry [9]. Electroanalytical techniques and screen-printing (thick-film) technology has made it possible to mass-produce inexpensive disposable electrodes for use with electrochemical instruments [10-14]. Their use in potentiometric, amperometric and voltammetric devices have been reported for the detection of heavy metals such as copper [15-18], lead [19-22], cadmium [20,22] and mercury [17] although there are few references in bibliography of their use in the determination of drugs [23].

Numerous experimental variables can affect the response when using stripping voltammetry techniques, calling for a process of optimizing the variables which will enable accurate measurements under the best possible conditions. In the improvement of any analytical procedure, special precautions need to be taken when choosing the experimental conditions, especially when it is a matter of trace level determination of species. An appropriately designed experiment [24, 25] provides signals of far superior quality to those measured in an experiment that has not been optimized. Likewise, the use of experimental designs allows exploring a wide experimental range for a reduced number of experiments. They are more efficient than the "one-at-a-time" optimization of experimental variables in analytical techniques [26-30]. As a result, in our work, experimental design has been used to establish appropriate experiments that will lead to the optimization of the influencing variables, such as, potential, deposition time $\left(\mathrm{E}_{\mathrm{dep}}, \mathrm{t}_{\mathrm{dep}}\right)$ and $\mathrm{pH}$ value.

\section{Results and Discussion}

\subsection{Stripping voltammetry of lamotrigine at the non modified CSPE.}

When differential pulse adsorptive stripping voltammetry (DPAdSV) analysis of LTG is carried out, using carbon screen-printed electrodes (CSPE) as working electrodes, a well defined reduction peak at $-1.16 \mathrm{~V}$ is observed (Figure 2). 
Figure 2. Differential pulse voltammograms obtained in Britton-Robinson ( $\mathrm{pH} 5$ ). Hg-CSPE: $t_{\text {dep }}=105 \mathrm{~s}, \mathrm{E}_{\mathrm{dep}}=0.40 \mathrm{~V}$ (1) Blank (2) $[\mathrm{LTG}]=1.5 \times 10^{-5} \mathrm{M}$. CSPE: $\mathrm{t}_{\mathrm{dep}}=28 \mathrm{~s}, \mathrm{E}_{\mathrm{dep}}=0.05 \mathrm{~V},(3)$ Blank (4) $[\mathrm{LTG}]=1.5 \times 10^{-5} \mathrm{M}$.

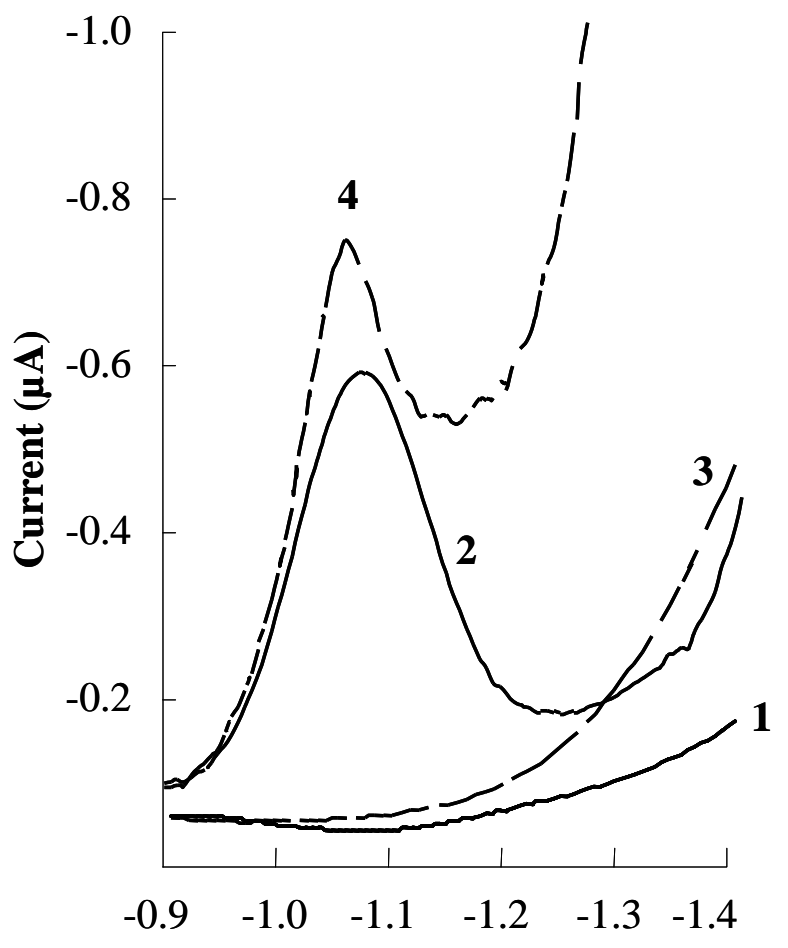

Potential (vs Ag/AgCl)

This peak is due to the following reduction process [9]:<smiles>[R]c1nnc([R])c([R])n1</smiles><smiles>[R]C1=NC([R])=C([R])NN1</smiles>

Judging from the response obtained, peak intensity $\left(i_{p}\right)$, was notably influenced by variables such as deposition time, $\mathrm{t}_{\mathrm{dep}}$, deposition potential, $\mathrm{E}_{\mathrm{dep}}$, and $\mathrm{pH}$, so an experimental design was used to optimize these parameters.

Prior to the experimental design stage, previous assays had shown that a very low electrochemical signal was obtained for $\mathrm{pH}$ values very different from 5.5. It was, therefore, decided to fix this factor and perform the optimization of the two remaining factors. A central composite design was chosen for this stage, its purpose being to arrange the factors and their interactions according to their influence on the peak current. These factors were $E_{\text {dep }}$ and $t_{\text {dep }}$. Subsequently, experiments with all possible combinations were carried out. The values which correspond to the high (+) and low (-) levels and to the central point $(0)$ for each factor were as follows,

$$
\begin{array}{lll}
\mathrm{E}_{\text {dep }}(+)=+0.30 \mathrm{~V} & \mathrm{E}_{\text {dep }}(-)=-0.30 \mathrm{~V} & \mathrm{E}_{\text {dep }}(0)=0 \mathrm{~V} \\
\mathrm{t}_{\text {dep }}(+)=50 \mathrm{~s} & \mathrm{t}_{\text {dep }}(-)=10 \mathrm{~s} & \mathrm{t}_{\text {dep }}(0)=30 \mathrm{~s}
\end{array}
$$


The response to be optimized was the intensity $\left(-\mathrm{i}_{\mathrm{P}}\right)$, of a lamotrigine sample at a concentration of $2.0 \times 10^{-5} \mathrm{M}$ at a potential peak of $-1.06 \mathrm{~V}$. From the analysis of the variance (ANOVA) of the data (Table 1), it can be seen that a second order function is adequate to model the data because the lack of fit is not significant at the $95 \%$ confidence level. It can also be deduced that the only significant factors are the $\mathrm{AA}$ and the $\mathrm{BB}$ interaction. However, a maximum can be observed in the response surface obtained for this design (Figure 3).

Table 1. ANOVA of the data obtained with the $2^{2}$ central composite design for optimization of experimental variables in LTG determination with CSPE by DPAdSV. $[\mathrm{LTG}]=2.0 \times 10^{-5} \mathrm{M}, \mathrm{pH}=5.5$

\begin{tabular}{lccccc}
\hline Effect & SS* & DF* & MS* & $\mathrm{F}_{\text {ratio }}^{*}$ & $\mathrm{P}_{\text {level }}{ }^{*}$ \\
\hline A: $\mathrm{E}_{\text {dep }}$ & 2478.870 & 1 & 2478.870 & 10.900 & 0.081 \\
B: $\mathrm{t}_{\text {dep }}$ & 1407.510 & 1 & 1407.510 & 6.190 & 0.131 \\
$\mathrm{AA}$ & 18565.500 & 1 & 18565.500 & 81.670 & $0.012(\mathrm{a})$ \\
$\mathrm{AB}$ & 5.664 & 1 & 5.664 & 0.020 & 0.889 \\
$\mathrm{BB}$ & 50502.10 & 1 & 50502.100 & 222.160 & $0.004(\mathrm{a})$ \\
Lack-of-fit & 4720.510 & 3 & 1573.500 & 6.920 & 0.129 \\
Pure error & 454.648 & 2 & 227.324 & & \\
Total & 64957.800 & 10 & & & \\
& $\mathrm{R}^{2}=92.033$ & & & & \\
\hline
\end{tabular}

* SS, sum of squares; DF, degrees of freedom; MS, mean squares;

$\mathrm{F}_{\text {ratio }}: \mathrm{MS}_{\text {factor }} / \mathrm{MS}_{\text {error }} ; \mathrm{P}_{\text {level }}$, probability level.

(a) Significant factor at $\alpha=0.05$.

Figure 3. Response surface for the $2^{2}$ central composite design for optimization of experimental variables in LTG determination by DPAdSV using CSPE electrodes.

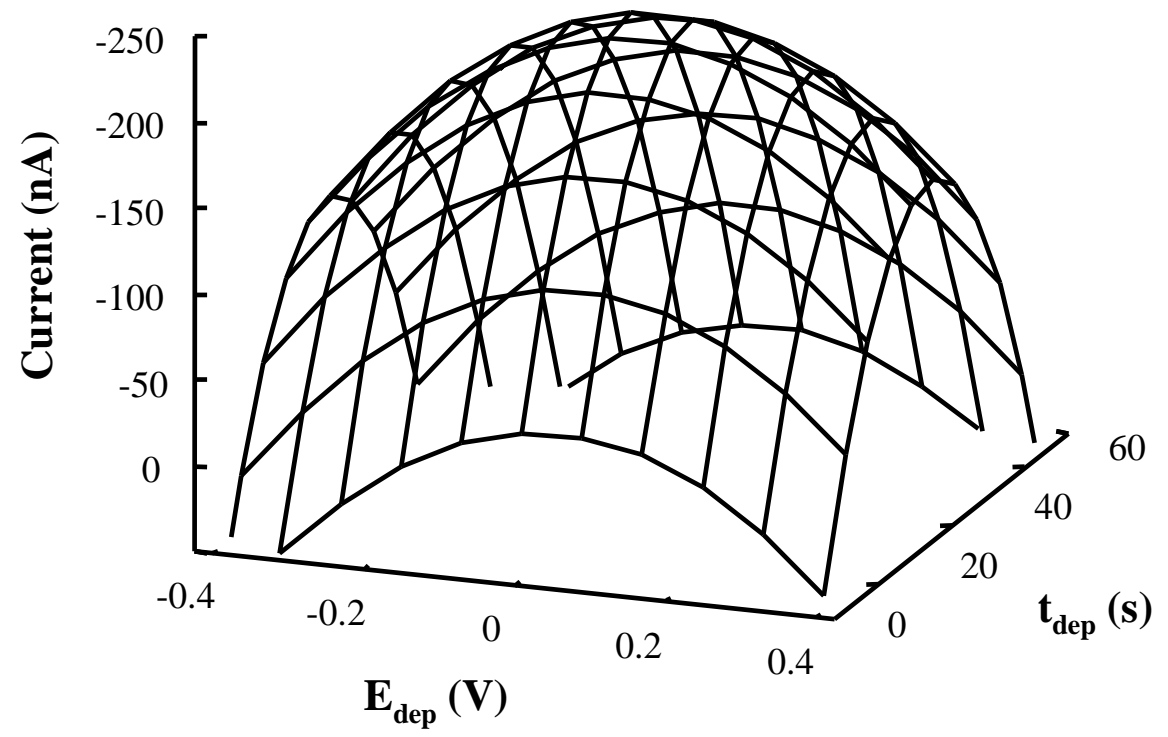


As a result of the above discussion, the optimum conditions for the determination of LTG by means of DPAdSV using the non modified-CSPE are:

$$
\mathrm{pH}=5.50 \mathrm{t}_{\mathrm{dep}}=28 \mathrm{~s} \quad \mathrm{E}_{\mathrm{dep}}=0.05 \mathrm{~V}
$$

\subsection{Stripping voltammetry of lamotrigine in $\mathrm{Hg}$ - coated CSPE.}

In this case, in order to carry out the analysis of LTG, the electrode was modified by depositing a mercury film on its surface.

When the analysis of LTG is performed by means of DPAdSV using Hg coated CSPE a reduction peak at $-1.06 \mathrm{~V}$ is observed (Figure 2). In this case, an optimization of the influencing experimental variables was also carry out.

Previous assays showed that the intensity of the electrochemical response for LTG increased when positive $E_{\text {dep }}$ were used, however the background noise suffered an important increasing when the potential of deposition was changed towards very positive values. For this reason, the deposition potential was fixed at $0.40 \mathrm{~V}$ due to the suitable quality of the signal obtained for this value.

The two remaining factors $\left(\mathrm{pH}\right.$ and $\mathrm{t}_{\mathrm{dep}}$ ) were optimized by means of a $2^{2}$ central composite design. The response to be optimized was the peak intensity obtained for a $1.5 \times 10^{-5} \mathrm{M}$ LTG solution. In the ANOVA test shown in Table 2 it can be seen that AA and BB interactions are both significant factors at a $95 \%$ confidence level, therefore, $\mathrm{pH}$ and $\mathrm{t}_{\mathrm{dep}}$ have to be considered as influence variables.

Table 2. ANOVA of the data obtained with the $2^{2}$ central composite design for optimization of experimental variables in LTG determination with $\mathrm{Hg}$ film modified CSPE by DPAdSV. [LTG] $=1.5 \times 10^{-5} \mathrm{M}, \mathrm{E}_{\mathrm{dep}}=0.40 \mathrm{~V}$

\begin{tabular}{lccccc}
\hline Effect & SS* & DF* & MS* & $\mathrm{F}_{\text {ratio }} *$ & $\mathrm{P}_{\text {level }} *$ \\
\hline A: $\mathrm{E}_{\text {dep }}$ & 292.47 & 1 & 292.47 & 0.10 & 0.78 \\
B: $\mathrm{t}_{\text {dep }}$ & 5943.26 & 1 & 5943.26 & 1.99 & 0.29 \\
$\mathrm{AA}$ & 201566.00 & 1 & 201566.00 & 67.65 & $0.01(\mathrm{a})$ \\
$\mathrm{AB}$ & 1.55 & 1 & 1.55 & 0 & 0.98 \\
BB & 104949.00 & 1 & 104949.00 & 35.23 & $0.03(\mathrm{a})$ \\
Lack-of-fit & 8847.37 & 3 & 2949.12 & 0.99 & 0.54 \\
Pure error & 5958.75 & 2 & 2979.38 & & \\
Total & 262926.00 & 10 & & & \\
& $\mathrm{R}^{2}=94.37$ & & & & \\
\hline
\end{tabular}

* SS, sum of squares; DF, degrees of freedom; MS, mean squares;

$\mathrm{F}_{\text {ratio }}: \mathrm{MS}_{\text {factor }} / \mathrm{MS}_{\text {error }} ; \mathrm{P}_{\text {level }}$, probability level.

(a) Significant factor at $\alpha=0.05$.

However, a maximum for the electrochemical response can be observed in Figure 4 which corresponds to the following values for the variables to be optimized: 


$$
\mathrm{pH}=5.53 \quad \mathrm{t}_{\mathrm{dep}}=105 \mathrm{~s}
$$

Figure 4. Level curves for the $2^{2}$ central composite design for optimization of experimental variables in LTG determination by DPAdSV with $\mathrm{Hg}$ film modified CSPE.

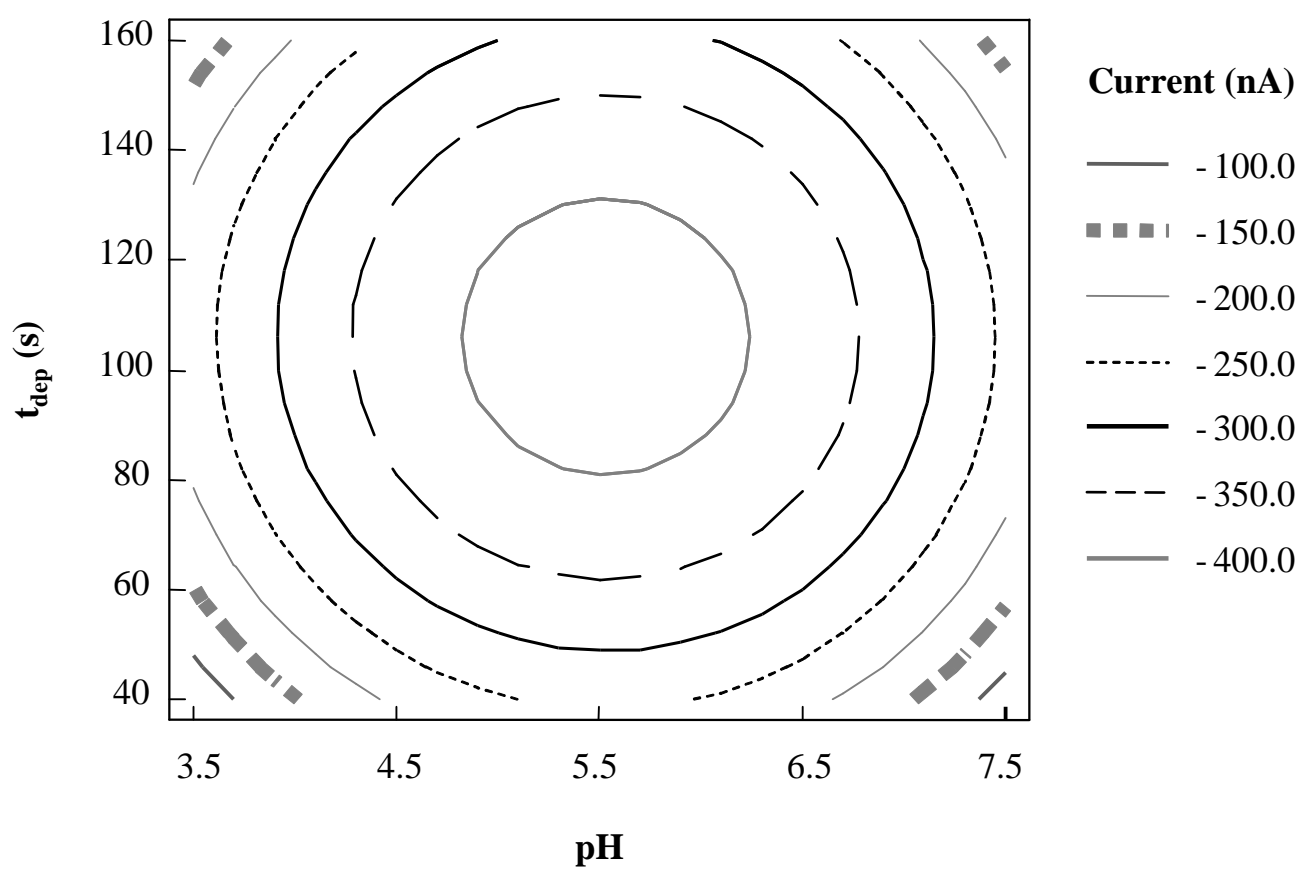

The electrochemical signal obtained with the Hg-coated CSPE is higher than the one obtained with the non modified CSPE. This fact allows the analysis of LTG at $\mathrm{pH}$ values different from 5.5 when using $\mathrm{Hg}$ modified CSPE. Nevertheless, it can be seen that even altering the $\mathrm{pH}$ the optimal value obtained is close to 5.53 .

\subsection{Calibration and Detection Limit.}

\subsubsection{Non modified CSPE.}

In order to determine the limit of detection of both procedures a calibration was performed, at low levels of concentration, using least-median-squares regression (LMS) to detect the existence of anomalous points [31], which might have led to incorrect adjustments altering the sensitivity and the detection limit. The criterion is to minimize the median of squares of the differences between the experimental and the calculated values. LMS Regression has the advantage of being able to detect anomalous points regardless of whether they are outliers or leverage points, seeking a linear range in which at least $50 \%$ of the data are aligned.

The strategy followed consisted of two steps. In the first, the LMS regression was used to detect anomalous points, taking outliers to be points where the absolute value of the standardized residual was greater than 2.50 and leverage points as those where the absolute value of their resistant diagnostic 
was greater than 2.50 . When both of these parameters were above 2.50 , the point was considered as an outlier-leverage. In a second step, the anomalous points detected in this way were eliminated and a regression based on the ordinary least squares (OLS) criterion was carried out, to obtain optimal precision and accuracy of both slope and intercept.

The calibration equation obtained by DPASV for standard solutions containing LTG concentrations of between $5.0 \times 10^{-6}$ and $2.1 \times 10^{-5} \mathrm{M}$ was:

$$
\begin{gathered}
-\mathrm{I}_{\mathrm{p}}=-421.81+5.23 \times 10^{7} \mathrm{C}_{\mathrm{LTG}} \\
\left(\mathrm{R}^{2}=0.99 \text { and Standard Deviation }\left(\mathrm{S}_{\mathrm{yx}}\right)=19.68\right)
\end{gathered}
$$

A key feature of an analytical method is the detection limit, the smallest concentration of the analyte that can be detected to a specified degree of certainty. The calculation of the detection limit, based on the variability of ten samples with a very low analyte concentration, was calculated according to [32] and ISO 11843-2 [33]. At the chosen probability level of 95\% $(\alpha=\beta=0.05)$, the detection limit was $5.0 \times 10^{-6} \mathrm{M}$.

\subsubsection{Hg-coated CSPE.}

The calibration equation obtained by DPASV for standard solutions containing LTG concentrations of between $2.0 \times 10^{-6}$ and $5.0 \times 10^{-6} \mathrm{M}$ was:

$$
\begin{gathered}
-\mathrm{I}_{\mathrm{p}}=-100.93+56.36 \times 10^{6} \mathrm{C}_{\mathrm{LTG}} \\
\left(\mathrm{R}^{2}=0.99 \text { and Standard Deviation }\left(\mathrm{S}_{\mathrm{yx}}\right)=0.08\right)
\end{gathered}
$$

In this case, at the chosen probability level of $95 \%(\alpha=\beta=0.05)$, the detection limit was $2.0 \times 10^{-6}$ M.

\subsection{Precision}

This parameter was calculated in terms of reproducibility. A series of 5 measurements of samples containing $1.5 \times 10^{-5} \mathrm{M}$ of LTG were carried out obtaining a \% RSD value of $9.83 \%$ for CSPE and $2.73 \%$ when a $\mathrm{Hg}$-coated CSPE was used. So, the $\mathrm{Hg}$ film modified CSPE resulted to be more precise.

From the above described results it can be deduced that the Hg-coated-CSPE is more useful for the analysis of LTG in terms of precision. For this reason this electrode has been chosen for the analysis of LTG in real samples.

\subsection{Linear Range}

The Hg-coated CSPE constructed as has been described in the previous sections resulted to offer a linear response in the range comprised between $2.0 \times 10^{-6}$ and $1.8 \times 10^{-5} \mathrm{M}\left(-\mathrm{I}_{\mathrm{p}}=141.59+40.60 \times 10^{6}\right.$ $\mathrm{C}_{\mathrm{LTG}} ; \mathrm{R}^{2}=0.99$ and Standard Deviation $\left.\left(\mathrm{S}_{\mathrm{yx}}\right)=14.43\right)$. 


\subsection{Determination of lamotrigine in real samples.}

The concentration of lamotrigine in commercial capsules of LAMICTAL ${ }^{\circledR}$ (GlaxoSmithKline) with a known concentration of analyte, was determined by standard addition using the DPAdSV using the mercury film modified CSPE, so as to evaluate the accuracy of the proposed method.

Good agreement was obtained between the amount found by the developed method $(24.5 \pm 0.8) \mathrm{mg}$ $(\mathrm{n}=3, \alpha=0.05)$ and the value supplied by the manufacturer $(25 \pm 1.2 \mathrm{mg})$. These results were also checked using the HPLC method described in [4] as a reference technique obtaining (25.2 \pm 1.1$) \mathrm{mg}$ $(\mathrm{n}=3, \alpha=0.05)$.

\section{Experimental Section}

\subsection{Reagents and chemicals}

Analytical grade chemicals not subjected to any further purification processes were used. All solutions were prepared with deionized water obtained using a Barnstead NANO Pure II system. Nitrogen $(99.99 \%)$ was used to remove dissolved oxygen.

Electrodag PF-407 A (carbon ink), Electrodag 418 SS (silver ink), Electrodag 6037 SS (silver/silverchloride ink) and Electrodag 452 SS (dielectric ink) were supplied by Achenson Colloiden (Scheemda, The Netherlands).

Solutions of lamotrigine were prepared by dissolving appropriate amounts of lamotrigine (Sigma, Steinheim, Germany) in water.

Britton-Robinson solutions were used as buffers. A 0.04 M Britton-Robinson buffer solution for the o-boric, o-phosphoric and acetic acids was prepared using Merck analytical grade reagents. Solutions of different $\mathrm{pH}$ values were prepared from this by the addition of $0.2 \mathrm{M}$ sodium hydroxide (analyticalreagent grade, Merck, Darmstadt, Germany).

Commercial capsules of LAMICTAL ${ }^{\circledR}$ were obtained from GlaxoSmithKline. The excipients of the tablet are: blackcurrant flavour, calcium carbonate, low-substituted hydroxypropylcellulose, magnesium aluminium silicate, magnesium stearate, povidone, saccharin sodium and starch glycolate).

In order to determine the concentration of LTG in LAMICTAL ${ }^{\circledR}$ tablets the following procedure was carried out: Ten tablets were pulverized with a pestle and a portion of the resulting powder was dissolved in water. The insoluble portion of the tablet was eliminated by filtration.

\subsection{Apparatus}

Screen-printed electrodes were produced on a DEK 248 printing machine (DEK, Weymouth, UK) using polyester screens with appropriate stencil designs mounted at $45^{\circ}$ to the printer stroke.

Voltammetric measurements were taken using a $\mu$ Autolab (Eco Chemie). The following values for the instrumental parameters were used: pulse amplitude, $-62 \mathrm{mV}$, staircase size, $4 \mathrm{mV}$ and duration of the pulse in the staircase potential sweep, $500 \mathrm{~ms}$.

The $\mathrm{pH}$ of the solution was measured with a Crison Model 2002 (Barcelona, Spain) pH meter. 


\subsection{Software}

Data analysis was processed with a STATGRAPHICS PLUS software package [34] for the experimental design process and PROGRESS [31] for the robust regression.

\subsection{Construction of Screen-printed Electrodes}

In this study, hand-made screen-printed electrodes were used in the determination of LTG. A threeelectrode configuration (working, reference and an auxiliary electrodes) was constructed for the determination of LTG. Since shape, surface area and spatial arrangement of the electrodes significantly influence the quality of the analytical response, the electrode system design deserves special attention. The design employed in this work is shown in Figure 5. In order to assemble the screen-printed electrodes, successive layers of different inks were printed onto a PVC strip substrate (30 mm x 15 $\mathrm{mm}, 0.5 \mathrm{~mm}$ thick) using four different screens with an appropriate stencil in order to reach the required design (Figure 5). The printing procedure was as follows:

1) Firstly, three parallel conducting base-patterns were printed with the commercial silver ink to give the screen-printed electrodes an effective conductive nature and were then cured for 15 minutes at $90{ }^{\circ} \mathrm{C}$. The base-pattern at the left was used as the counter electrode.

2) A silver/silver chloride reference electrode was printed using silver/silver chloride ink on the silver base-pattern at the right, as can be seen in Figure 5, and then cured for 15 minutes at $90{ }^{\circ} \mathrm{C}$.

3 ) The working electrode was formed by printing a graphite layer over the silver base-pattern at the center using commercial graphite ink and was then cured for 15 minutes at $90{ }^{\circ} \mathrm{C}$.

4) Finally, excepting the surface of the three electrodes and the electrical connection at the reverse end of the sensor strip, an insulator layer was printed over the sensor strip and then cured by UV radiation.

Figure 5. Schematic diagram of the sensor preparation procedure.

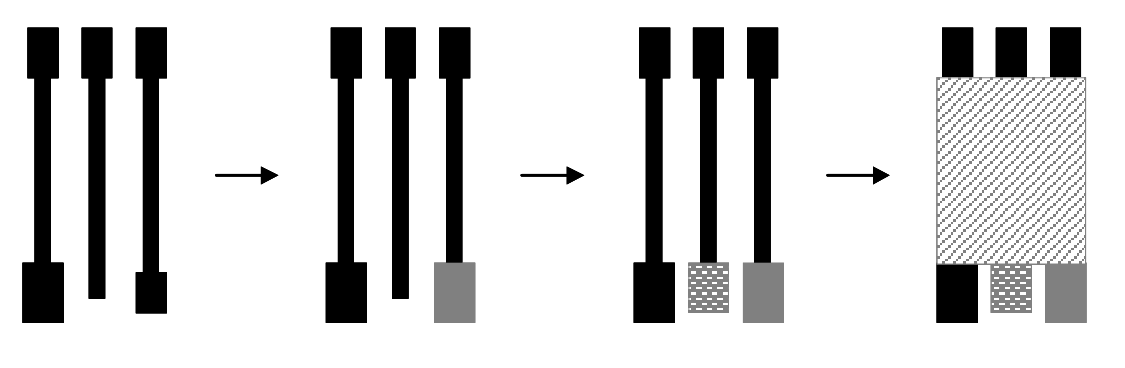

1.Silver base-patterns 2. $\mathrm{Ag} / \mathrm{AgCl}$ layer $\quad$ 3.Graphite layer $\quad$ 4.Insulator layer

\subsection{Mercury film preparation}

In a separate process, the mercury film was coated over the screen-printed working electrode surface, using a solution containing $800 \mathrm{mg} \mathrm{L}^{-1}$ of $\mathrm{HgCl}_{2}$. Good analytical signals in the analysis of LTG were obtained when the deposition of the mercury film was performed by applying a potential of - $0.9 \mathrm{~V}$ during $600 \mathrm{~s}$ under stirring in $1.3 \mathrm{M} \mathrm{HCl}$ solution. 


\subsection{Stripping voltammetry measurements.}

Voltammetric measurements were taken using the following procedure: the solution was purged using nitrogen, and stirred for $300 \mathrm{~s}$, the deposition potential was then applied for the time and potential as determined for each experiment. The solution was left to rest for an equilibrium time of 5 $\mathrm{s}$, then a cathodic scan from $0 \mathrm{~V}$ (initial potential) to $-1.40 \mathrm{~V}$ (final potential) was started and the voltammogram recorded, using a potential step of $6.00 \mathrm{mV}$. The modulation time was $0.04 \mathrm{~s}$ and the interval time of the applied pulses was $0.60 \mathrm{~s}$.

Non modified CSPEs electrodes can be used only for one measurement whereas Hg-coated SCPE can be used several for several measurements.

\section{Conclusions}

The Hg-modified carbon screen printed electrodes developed in this work present an interesting method for the analysis of LTG. One of the interesting contributions of this work is the viability of performing analysis of LTG in pharmaceutical preparations in an easy way using simple regression because no effect from the sample matrix was found. This analysis is more difficult when using other electrodes such as a HDME where a multivariate calibration was necessary [9]. Moreover, the proposed method is a more environmental friendly form to determine LTG.

\section{Acknowledgements}

The financial support made available by the Junta de Castilla y León (BU022A07) and the Ministerio de Educación y Ciencia (MAT2005-01767) is gratefully acknowledged. M. Encarnación Burgoa Calvo also thanks to Consejería de Educación de la Junta de Castilla y León and Fondo Social Europeo for the F.P.I. grant.

\section{References and Notes}

1. Bialer, M.; Johannessen, S.I.; Kupferberg, H.J.; Levy, R.H.; Loiseau, P.; Perucca, E. Progress report on new antiepileptic drugs: a summary of the fourth Eilat conference (EILAT IV). Epilepsy Research 1999, 34, 1-41.

2. Shorvon, S.; Stefan, H. Overview of the safety of newer antiepileptic drugs. Epilepsia 1997, 38, S45-S51.

3. Londero, D.; LoGreco, P. New micromethod for the determination of lamotrigine in human plasma by high-performance liquid chromatography. Journal of Chromatography B 1997, 691, 139-144.

4. Matar, K.M.; Nicholls, P.J.; Bawazir, S.A.; Al-Hassan, M.I.; Tekle, A. A rapid liquid chromatographic method for the determination of lamotrigine in plasma. Journal of Pharmaceutical and Biomedical Analysis 1998, 17, 525-531.

5. Angelis-Stoforidis, P.; Morgan, D.J.; O'Brien, T.J.; Vajda, F.J.E. Determination of lamotrigine in human plasma by high-performance liquid chromatography. Journal of Chromatography B 1999, 727, 113-118. 
6. Vidal, E.; Pascual, C.; Pou, L. Determination of lamotrigine in human serum by liquid chromatography. Journal of Chromatography B 1999, 736, 295-298.

7. Barbosa, N.R.; Midio, A.F. Validated high-performance liquid chromatographic method for the determination of lamotrigine in human plasma. Journal of Chromatography B 2000, 741, 289293.

8. Zheng, J.; Jann, M.W.; Hon, Y.Y.; Shamsi, S.A. Development of capillary zone electrophoresiselectrospray ionization-mass spectrometry for the determination of lamotrigine in human plasma. Electrophoresis 2004, 25, 2033-2043.

9. Calvo, M.E.B.; Renedo, O.D.; Martinez, M.J.A. Optimization of the experimental parameters in the determination of lamotrigine by adsorptive stripping voltammetry. Analytica Chimica Acta 2005, 549, 74-80.

10. Wang, J.; Lu, J.M.; Tian, B.M.; Yarnitzky, C. Screen-printed ultramicroelectrode arrays for onsite stripping measurements of trace-metals. Journal of Electroanalytical Chemistry 1993, 361, 77-83.

11. Yarnitzky, C.; Wang, J.; Tian, B.M. Hand-held lead analyzer. Talanta 2000, 51, 333-338.

12. Ugo, P.; Moretto, L.M.; Bertoncello, P.; Wang, J. Determination of trace mercury in saltwaters at screen-printed electrodes modified with sumichelate Q10R. Electroanalysis 1998, 10, 1017-1021.

13. Desmond, D.; Lane, B.; Alderman, J.; Hill, M.; Arrigan, D.W.M.; Glennon, J.D. An environmental monitoring system for trace metals using stripping voltammetry. Sensors and Actuators B-Chemical 1998, 48, 409-414.

14. Jasinski, M.; Grundler, P.; Flechsig, G.U.; Wang, J. Anodic stripping voltammetry with a heated mercury film on a screen-printed carbon electrode. Electroanalysis 2001, 13, 34-36.

15. Beni, V.; Ogurtsov, V.I.; Bakunin, N.V.; Arrigan, D.W.M.; Hill, M. Development of a portable electroanalytical system for the stripping voltammetry of metals: Determination of copper in acetic acid soil extracts. Analytica Chimica Acta 2005, 552, 190-200.

16. Palchetti, H.; Laschi, S.; Mascini, M. Miniaturised stripping-based carbon modified sensor for in field analysis of heavy metals. Analytica Chimica Acta 2005, 530, 61-67.

17. Rodriguez, B.B.; Bolbot, J.A.; Tothill, I.E. Urease-glutamic dehydrogenase biosensor for screening heavy metals in water and soil samples. Analytical and Bioanalytical Chemistry 2004, 380, 284-292.

18. Honeychurch, K.C.; Hawkins, D.M.; Hart, J.P.; Cowell, D.C. Voltammetric behaviour and trace determination of copper at a mercury-free screen-printed carbon electrode. Talanta 2002, 57, 565574.

19. Kadara, R.O.; Tothill, L.E. Resolving the copper interference effect on the stripping chronopotentiometric response of lead(II) obtained at bismuth film screen-printed electrode. Talanta 2005, 66, 1089-1093.

20. Palchetti, I.; Majid, S.; Kicela, A.; Marrazza, G.; Mascini, M. Polymer-mercury coated screenprinted sensors for electrochemical stripping analysis of heavy metals. International Journal of Environmental Analytical Chemistry 2003, 83, 701-711.

21. Zen, J.M.; Yang, C.C.; Kumar, A.S. Voltammetric behavior and trace determination of Pb2+ at a mercury-free screen-printed silver electrode. Analytica Chimica Acta 2002, 464, 229-235. 
22. Choi, J.Y.; Seo, K.; Cho, S.R.; Oh, J.R.; Kahng, S.H.; Park, J. Screen-printed anodic stripping voltammetric sensor containing $\mathrm{HgO}$ for heavy metal analysis. Analytica Chimica Acta 2001, 443, 241-247.

23. Shih, Y.; Zen, J.M.; Yang, H.H. Determination of codeine in urine and drug formulations using a clay-modified screen-printed carbon electrode. Journal of Pharmaceutical and Biomedical Analysis 2002, 29, 827-833.

24. Box, G.E.P.H., Hunter, N.G.; Hunter, J.S., Estadística para investigadores. Introducción al diseño de experimentos. Análisis de datos y construcción de modelos. Reverté: Barcelona, 1989.

25. Morgan, E., Chemometrics: Experimental Design. Wiley: New York, 1991.

26. Gratteri, P.; Furlanetto, S.; Pinzauti, S.; Leardi, R.; Corti, P. Optimization by experimental design of the adsorptive stripping voltammetric parameters in the determination of cinoxacin. Electroanalysis 1995, 7, 1161-1164.

27. Dominguez, O.; Sanllorente, S.; Arcos, M.J. Application of an optimization procedure of adsorptive stripping voltammetry for the determination of chromium in wine. Electroanalysis 1999, 11, 1273-1279.

28. Dominguez, O.; Sanllorente, S.; Alonso, M.A.; Arcos, M.J. Application of an optimization procedure for the determination of chromium in various water types by catalytic-adsorptive stripping voltammetry. Electroanalysis 2001, 13, 1505-1512.

29. Gonzalez, M.J.G.; Renedo, O.D.; Lomillo, M.A.A.; Martinez, M.J.A. Determination of gallium by adsorptive stripping voltammetry. Talanta 2004, 62, 457-462.

30. Paolicchi, I.; Renedo, O.D.; Lomillo, M.A.A.; Martinez, M.J.A. Application of an optimization procedure in adsorptive stripping voltammetry for the determination of trace contaminant metals in aqueous medium. Analytica Chimica Acta 2004, 511, 223-229.

31. Rousseuw, P.J.; Leroy, A.M. Robust Regression and Outlier Detection, Wiley: New York, 1989.

32. Massart, D.L.; Vandeginste, B.G.M.; Deming, S.N.; Michotte, Y.; Kaufman, L. Handbook of Chemometrics and Qualimetrics, Part A. Elsevier: Armsterdam, 1997.

33. ISO11843-2, I., Capability of Detection. 2000, Switzerland.

34. Statistical Graphics Corp. Statgraphics PLUS for Windows, Version 4.0. 1994-1999.

(C) 2008 by the authors; licensee Molecular Diversity Preservation International, Basel, Switzerland. This article is an open-access article distributed under the terms and conditions of the Creative Commons Attribution license (http://creativecommons.org/licenses/by/3.0/). 